九州大学学術情報リポジトリ

Kyushu University Institutional Repository

\title{
Design and Experiment of a Semiphysical Simulation Platform of the Lifting System of a Tractor with an Adaptive Function
}

LI, Mingsheng

College of Engineering and Technology, Southwest University, China

MITSUOKA, Muneshi

Laboratory of Agricultural Machinery and Production Systems Design, Division of Bioproduction Environmental Sciences, Department of Agro-environmental Sciences, Faculty of Agriculture, Kyushu University

INOUE, Ei ji

Laboratory of Agricultural Machinery and Production Systems Design, Division of Bioproduction Environmental Sciences, Department of Agro-environmental Sciences, Faculty of Agriculture, Kyushu University

OKAYASU, Takashi

Laboratory of Agricultural Machinery and Production Systems Design, Division of Bioproduction Environmental Sciences, Department of Agro-environmental Sciences, Faculty of Agriculture, Kyushu University

他

https://doi. org/10.5109/2340994

出版情報：九州大学大学院農学研究院紀要. 64 (2)，pp.319-325，2019-09-02. Faculty of Agriculture, Kyushu University

バージョン :

権利関係 : 


\title{
Design and Experiment of a Semiphysical Simulation Platform of the Lifting System of a Tractor with an Adaptive Function
}

\author{
Mingsheng LI ${ }^{1 *}$, Muneshi MITSUOKA ${ }^{2}$, Eiji INOUE ${ }^{2}$, Takashi OKAYASU ${ }^{2}$, \\ Ya-sumaru HIRAI ${ }^{2}$ and Jian LIU ${ }^{1}$
}

\author{
Laboratory of Agricultural Machinery and Production Systems Design, Division of Bioproduction \\ Environmental Sciences, Department of Agro-environmental Sciences, Faculty of Agriculture, \\ Kyushu University, Fukuoka 819-0395, Japan \\ (Received May 7, 2019 and accepted May 8, 2019)
}

\begin{abstract}
The control performance of the lifting system of a tractor needs to be further improved in terms of adaptability to the operating environment. This paper presents a mixed simulation method based on MATLAB and LabVIEW, proposes a fuzzy proportional-integral-derivative adaptive control algorithm, and designs a semiphysical simulation platform of the lifting system of a tractor with an adaptive function. The above achievements were applied to field experiments. In a depth control experiment, the adjustment time was $5 \mathrm{~s}$ and the maximum overshoot was $90 \%$ when the tillage depth decreased from 20 to $10 \mathrm{~cm}$ while the adjustment time was $18 \mathrm{~s}$ and the maximum overshoot was $20 \%$ when the tillage depth increased from 10 to $25 \mathrm{~cm}$. In a traction control experiment, the adjustment time was $1.4 \mathrm{~s}$ and the maximum overshoot was $25 \%$ when the traction force increased from 3000 to $7000 \mathrm{~N}$ while the adjustment time was $2 \mathrm{~s}$ and the maximum overshoot was $51 \%$ when the traction force decreased from 7000 to $2000 \mathrm{~N}$. In a traction and tillage depth joint control experiment, the steady-state errors of the traction force and ploughing depth were respectively $\pm 4000 \mathrm{~N}$ and $\pm 5.5 \mathrm{~cm}$.
\end{abstract}

Key words: Tractor, Lifting system, Semiphysical simulation, Fuzzy proportional-integral-derivative algorithm

\section{INTRODUCTION}

The lifting system of a tractor is used to control the lifting and tillage of agricultural tools. The performance of the lifting system directly affects the quality and efficiency of tractor operation. The widespread use of integral agricultural instruments has required lifting system with certain features; e.g., a hydraulic system with an adequate lifting capacity (Johannsen, 1954). A machine-liquid lifting system was thus developed for farming tractors. To increase accuracy and functionality, an electronically controlled lifting system, referred to as an electrohydraulic lifting system, was subsequently developed (Dell Acqua et al., 1986) and has replaced the machine-liquid lifting system.

The control algorithm most commonly used in electrohydraulic lifting is the propor-tional-integral-derivative (PID) control algorithm (X. Ha et al., 2017). However, the algorithm has many deficiencies, with the most prominent being the PID parameter problem. Traditional PID control parameters are fixed and must be set relative to a known system. Traditional PID control thus does not meet system requirements because of uncertainties in the control process due to nonlinear factors in the mechanical and hydraulic systems. System

\footnotetext{
1 College of Engineering and Technology, Southwest University, China

2 Laboratory of Agricultural Machinery and Production Systems Design, Division of Bioproduction Environmental Sciences, Department of Agro-environmental Sciences, Faculty of Agriculture, Kyushu University, Japan

* Corresponding author (E-mail: limingshengSWU@vip.163. com)
}

requirements can be met, however, by an adaptive algorithm that combines a fuzzy control algorithm and PID control algorithm. According to the operating conditions of a tractor, PID parameters are calculated by a fuzzy algorithm and adjusted in real time.

MATLAB and LabVIEW have been separately used as software tools to simulate and test the performance of electrohydraulic lift systems and thus further improve the performance of an electrohydraulic lifting system (Xie. B et al., 2013; J.B.W.Roeber et al., 2016). MATLAB is powerful in computing, simulation, and mapping but not in interface development, instrument connection control, or network communication. By combining the two software packages, researchers can take full advantage of their advantages and easily connect instruments and conduct mathematical analysis.

The present study develops a fuzzy-PID adaptive control algorithm and builds a semi-physical simulation platform of the electrohydraulic lifting system through the combined use of MATLAB and LabVIEW. The experimental system comprises a tractor and force and depth sensing subsystems. An experiment was conducted on a farm to analyze the performance of the electrohydraulic lifting system.

\section{MATERIALS AND METHODS}

\section{General platform design}

On the semiphysical simulation platform, some parts of simulation objects are placed into the simulation circuit in a real way and the remaining parts are converted into a mathematical simulation model, and a real-time simulation and physical simulation are then performed 
using the physical effect model. Figure 1 shows the composition of the semiphysical simulation platform, including the measured object, computer simulation software system, and interface of hardware and software.

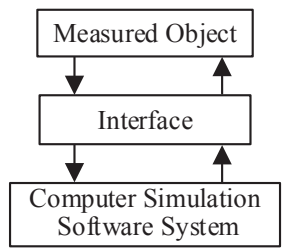

Fig. 1. Composition of the semiphysical simulation platform.

Figure 2 shows the structure of the platform built for the electrohydraulic lifting system of the tractor, including the physical part, software part, and interface part. The physical part includes an electromagnetic valve, tractor hydraulic circuit, lifting mechanism, and sensor. The electromagnetic proportional valve controls the lifting and lowering of the lifting mechanism by controlling the flow direction of oil in the hydraulic circuit. The sensor monitors the position of the lifting mechanism and converts it into an electrical signal that is sent to the controller. The software part includes MATLAB and LabVIEW, where the mathematical model of the controller is built to simulate the functions of the controller. The controller model receives the sensor signal from the physical part. After signals are compared in the controller mathematical model, the control signal is sent to the electromagnetic proportional valve of the physical part to control the movement of the lifting mechanism through the hydraulic circuit. The interface part includes the interface of MATLAB and LabVIEW software and the interface of physical hardware and software.

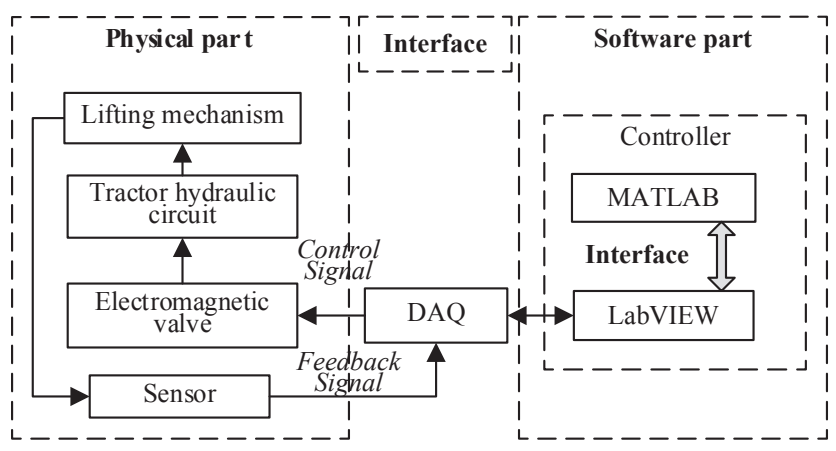

Fig. 2. Structure of the semiphysical simulation platform.

\section{Interface design}

The signal interaction between the hardware part and software part of the semiphysical simulation platform should be achieved through a stable and reliable interface. A USB-6216 multifunction data acquisition card (DAQ) is used as an interface for signal communication. The USB-6216 DAQ converts sensor signals from the physical part into signals that are read and displayed by LabVIEW software and amplifies the control signals from the software and converts them into voltage signals that drive the electromagnetic valve, thereby allowing communication between the physical and software parts.

The Simulation Interface Toolkit (SIT) provides a good software interface for MATLAB and LabVIEW and is used in this study. Figure 3 shows the mixed programming model. The program used for the reception of operation instructions, data acquisition, communication, and display was designed in LabVIEW, the control algorithm was written in MATLAB, and the communication between LabVIEW and MATLAB was realized by the SIT to simulate the controller function.

Simulation Interface Toolkit

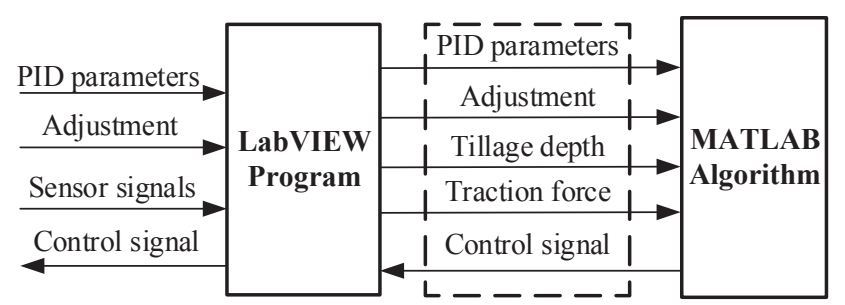

Fig. 3. Mixed programming model.

\section{Software development \\ LabVIEW program}

LabVIEW provides users with a convenient and fast human-computer interface. Figure 4 shows the humanmachine interaction interface of the semiphysical simulation platform of the electrohydraulic lifting system of the tractor established in this study. The interface comprises four parts, namely the control of PID parameters, display of hardware control signals, display of MATLAB simulation results, and storage of data.

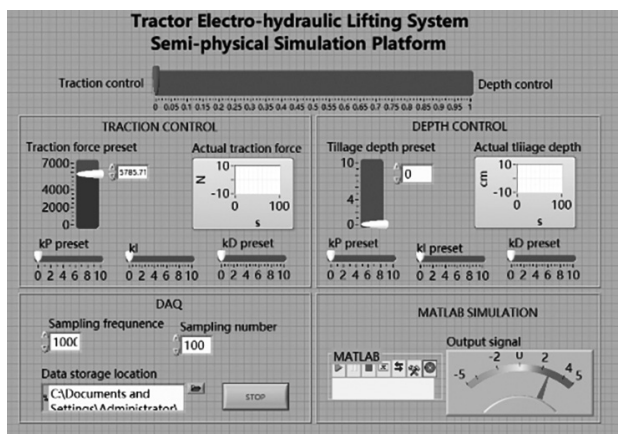

Fig. 4. Human-machine interaction interface of the semiphysical simulation platform.

The PID parameter control section modifies the initial control parameters KP, KI, and KD of the PID algorithm and sets the target tillage depth and tillage dead zone. The hardware control signal display section displays the control signal for the electrohydraulic proportional valve of the tractor electrohydraulic lifter, with the control signal being in the form of a pulse-width modulation signal. The MATLAB simulation control section controls the starting and stopping of the MATLAB simulation program and displays the MATLAB simulation results in the form of a pointer. The data storage section sets the sampling frequency and saves the simulation 
result on the specified path.

\section{Adaptive control algorithm}

The mathematical model of the controller is preestablished using the modeling function of MATLAB. The adaptive control algorithm designed in this study is a fuzzy-PID adaptive control that comprises two parts, namely conventional PID control and fuzzy reasoning. The fuzzy reasoning part is essentially a fuzzy controller whose inputs include the deviation and the deviation rate of change.

The principle of the fuzzy self-tuning of PID parameters is to determine the fuzzy relationship between PID parameters and input signals (including the deviation and deviation rate). In the process of controlling the system operation, the calculation program realizes the PID parameters in real time by constantly querying the fuzzy control rules.

Figure 5 shows the application of the fuzzy-PID adaptive control algorithm of the semi-physical simulation platform for the electrohydraulic lifting system of a tractor. The fuzzy-PID controller input variables include the deviation between the traction force/tillage depth preset by the LabVIEW human interface and the traction force/tillage depth measured by sensors and the change rate of the deviation. The output is the voltage that controls the electromagnetic proportional valve.

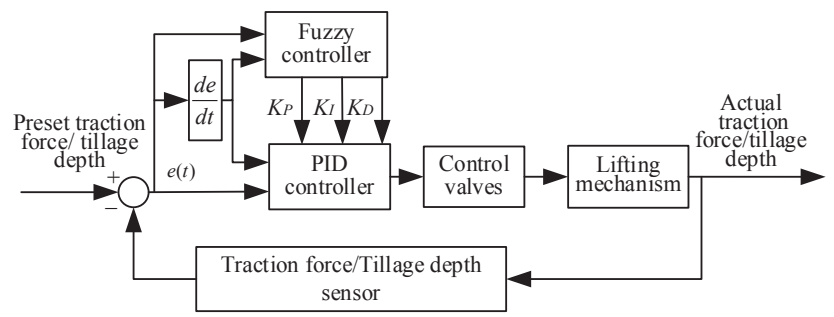

Fig. 5. Application of the fuzzy-PID adaptive control algorithm.

\section{Fuzzy control algorithm}

(1) Input variables, output variables, and domains The input variables of the fuzzy controller are the deviation $e$ of the preset traction force from the soil resistance and the deviation rate $e c$. The output variables are the parameters $\Delta K_{P}, \Delta K_{I}$, and $\Delta K_{D}$. The basic domains of $e, e c, \Delta K_{P}, \Delta K_{I}$, and $\Delta K_{D}$ are respectively [ $-e$, e], [-ec,ec], $\left[-\Delta K_{P}, \Delta K_{P}\right],\left[-\Delta K_{I}, \Delta K_{I}\right],\left[-\Delta K_{D}, \Delta K_{D}\right]$. The fuzzy controller only receives discrete data but the platform variables are continuous and the domains must therefore be discretized. The quantization of each variable is of level 7 . Table 1 gives the discrete domain of each variable.

(2) Variable-domain fuzzy subsets

The present study uses a fuzzy set of low-resolution membership functions to improve system stability and a fuzzy set of high-resolution membership functions for systems with small or near-zero errors to improve system sensitivity. The fuzzy controller uses the trian-gular membership function, with each variable having seven fuzzy subsets, which are negative big (NB), negative middle (NM), negative small (NS), zero (Z), positive small (PS), positive middle (PM), and positive big (PB). $\mathrm{NB}$ is a Z-type membership function, $\mathrm{PB}$ is an S-type membership function, and the other subsets are triangular membership functions. Figure 6 shows the membership functions of each variable.

(3) Fuzzy control rules

In the design of the fuzzy-PID controller, fuzzy rules are determined in accordance with three principles. (1) When the deviation $e$ is large, to improve the system response speed, the proportion value is taken larger, the differential value is taken smaller, and the integral value is as small as possible to suppress the effect of the integral. (2) When the deviation e is a mid-range value, the proportion value is taken smaller to reduce the overshoot. (3) When the deviation e is small, the proportion

Table 1. Domains of the electrohydraulic lifting system of a tractor

\begin{tabular}{cccc}
\hline & Basic domain & Quantitative domain & Quantization factor \\
\hline$e$ & {$[-6,+6]$} & {$[-3,+3]$} & 0.5 \\
$e c$ & {$[-1.2,+1.2]$} & {$[-3,+3]$} & 2.5 \\
$\Delta K_{P}$ & {$[-0.09,+0.09]$} & {$[-3,+3]$} & 0.03 \\
$\Delta K_{I}$ & {$[-0.3,+0.3]$} & {$[-3,+3]$} & 0.1 \\
$\Delta K_{D}$ & {$[-0.0015,+0.0015]$} & {$[-3,+3]$} & 0.0005 \\
\hline
\end{tabular}

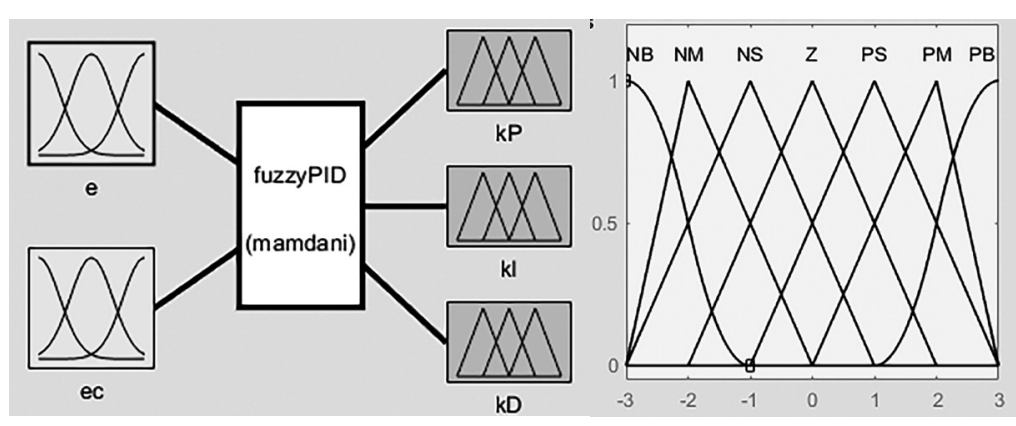

Fig. 6. Membership functions of each variable. 
and integral values are taken larger to reduce stability error; meanwhile, the differential value is adjusted to reduce system oscillation. Table 2 gives the developed fuzzy control rules.

(4) Fuzzy-PID adaptive control model

Figure 7 shows the fuzzy-PID adaptive controller model established in MATLAB. After the input of the deviation $e$ and deviation rate $e c$, the fuzzy inference engine corrects the PID parameters according to the quantized deviation signal and the deviation-rate signal and then outputs the control voltage signal.

\section{Experimental Device}

An experiment was conducted to test the control performance of the semiphysical simu-lation platform of the tractor lifting system with a fuzzy-PID adaptive control algorithm. Monitoring data were the tractor preset and actual tractions, tractor preset, and actual tillage depth. Analysis of the data reflects the response performance of the platform. Figure 8 shows the experimental platform of the electrohydraulic lifting system of the tractor.

The tillage depth was measured by a noncontact tilt sensor mounted on the lift arm while the depth was calculated by measuring the angle of the lift arm. The tillage depth sensor was calibrated before the experiment. Figure 9 shows the installation position and calibration curve of the tillage depth sensor. Formulas of conversion between the tillage depth and sensor were obtained by data fitting:

$$
\mathrm{y}=-29.31 \mathrm{x}+102.93 \text {. }
$$

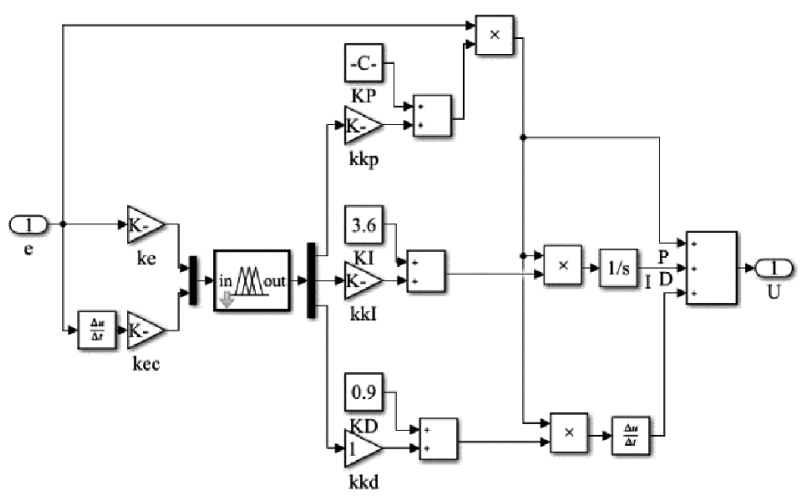

Fig. 7. Fuzzy-PID adaptive controller model.

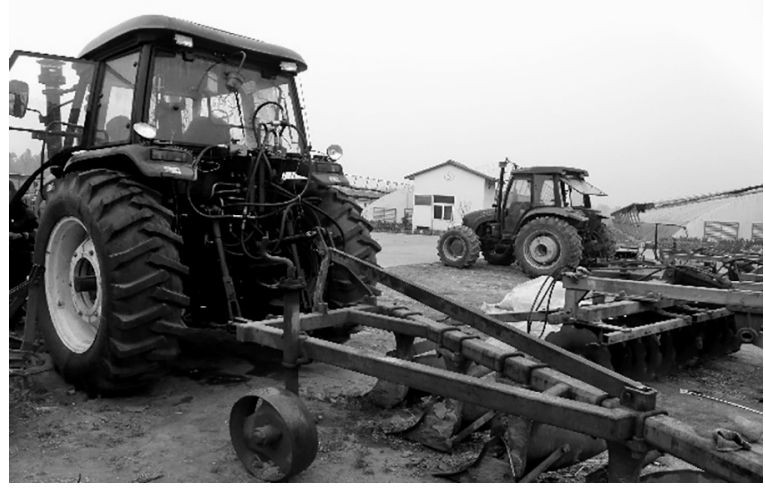

Fig. 8. Experimental platform of the electrohydraulic lifting system of a tractor.

Table 2. Fuzzy control rules of $\Delta K P, \Delta K I$, and $\Delta K D$

\begin{tabular}{cccccccc}
\hline & \multicolumn{7}{c}{$e c$} \\
\cline { 2 - 7 } & NB & NM & NS & Z & PS & PM & PB \\
\hline NB & NB NB PS & NB NB NS & NB NM NB & NB NM NB & NB NS NB & NB Z NM & NB Z PS \\
NM & PB NB PS & PB NB NS & PM NM NB & PS NS NM & PS NS NM & Z Z NS & NS NS Z \\
NS & PM NB Z & PM NM NS & PM NS NM & PS NS NM & Z Z NS & NS PS NS & NS PS Z \\
Z & PM NM Z & PM NM NS & PS NS NS & Z Z NS & NS PS NS & NM PM NS & NM PM Z \\
PS & PS NM Z & PS NS Z & Z Z Z & NS PS NS & NS PS Z & NM PM Z & NM PB Z \\
PM & PS Z PB & Z Z PS & NS PS PS & NM PM PS & NM PM PS & NM PB PS & NB PB PB \\
PB & Z Z PB & Z Z PM & NM PS PM & NM PM PM & NM PM PS & NB PB PS & NB PB PB \\
\hline
\end{tabular}
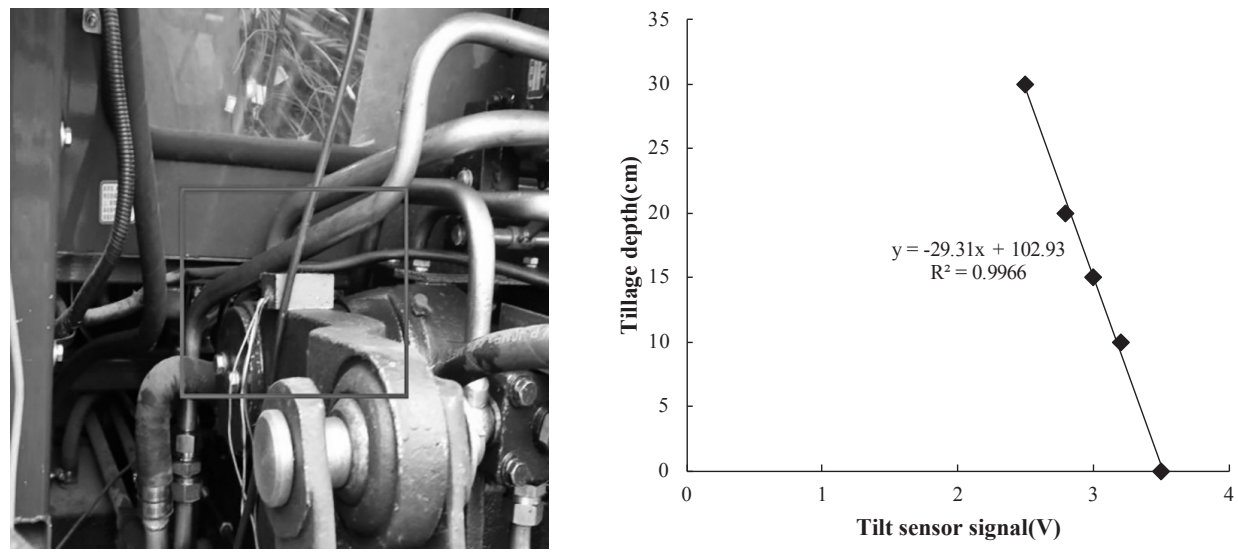

Fig. 9. Installation position and calibration curve of the tillage depth sensor. 

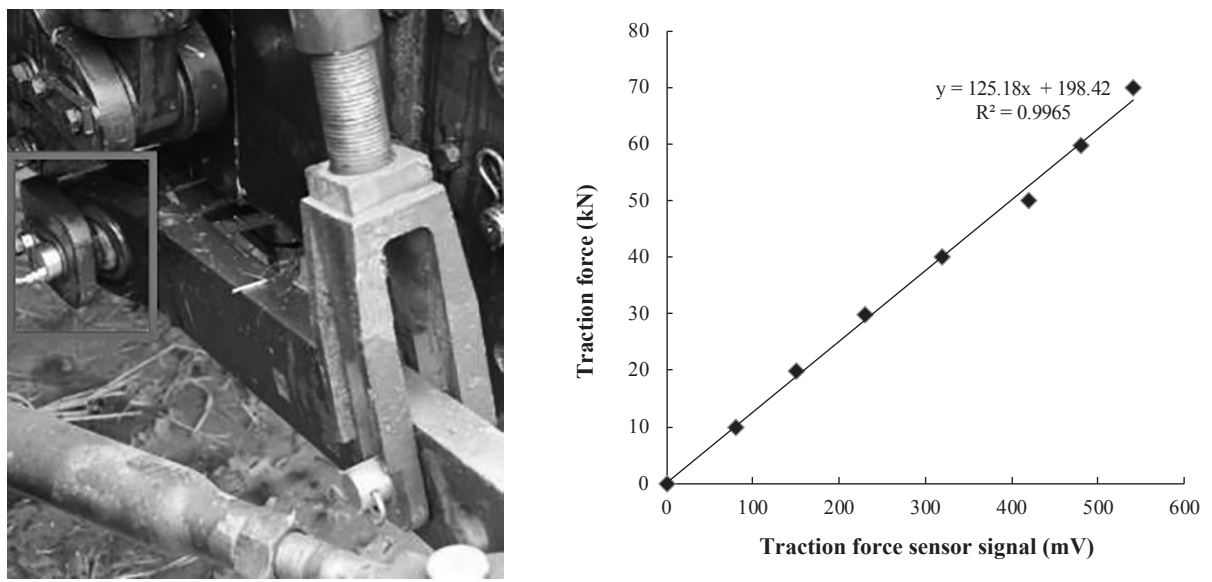

Fig. 10. Installation position and calibration curve of the traction force sensor.

The traction force was measured by two pin-type force sensors. The traction force sensors were installed on the left and right pull rods of the tractor. The actual traction force of the tractor was the sum of the forces measured by the two sensors. Figure 10 shows the installation position and calibration curve of the traction force sensor. Formulas of conversion between the traction force and sensor data were obtained by data fitting:

$$
\mathrm{y}=125.18 \mathrm{x}+198.42 \text {. }
$$

\section{RESULTS AND DISCUSSION}

The field tests were conducted at the China Agricultural University Experimental Station, Beijing. The tractor speed was set at $8.6 \mathrm{~km} / \mathrm{h}$. Three working conditions were tested according to the ploughing mode of the tractor. They were the working conditions of depth control, traction control, and combined traction and depth control.

The purpose of the depth control experiment was to control the tillage depth at a preset value. The tillage depth was set to $20 \mathrm{~cm}$ at first, $10 \mathrm{~cm}$ after $22 \mathrm{~s}$, and $25 \mathrm{~cm}$ after $43 \mathrm{~s}$. Figure 11 shows the variations in the actual tillage depth and traction with the set tillage depth. When the tillage depth decreased from 20 to $10 \mathrm{~cm}$, the adjustment time was $5 \mathrm{~s}$ and the maximum overshoot was $90 \%$. When the tillage depth increased from 10 to $25 \mathrm{~cm}$, the adjustment time was $18 \mathrm{~s}$ and the maximum overshoot was 20\%. The steady-state error of tillage depth was $\pm 2 \mathrm{~cm}$ over the course of the experiment.

The purpose of the traction control experiment was to keep the traction at a preset value. The traction force was set to $3000 \mathrm{~N}$ first, $7000 \mathrm{~N}$ after $27 \mathrm{~s}$, and $4000 \mathrm{~N}$ after $98 \mathrm{~s}$. Figure 12 shows the variations of actual traction and tillage depth with the set traction. When the traction force increased from 3000 to $7000 \mathrm{~N}$, the adjustment time was $1.4 \mathrm{~s}$ and the maximum overshoot was $25 \%$. When the traction force decreased from 7000 to $2000 \mathrm{~N}$, the adjustment time was $2 \mathrm{~s}$ and the maximum overshoot was $51 \%$. The steady-state error of the traction force was $\pm 1200 \mathrm{~N}$ over the course of the experiment.

The purpose of the traction and tillage depth joint control experiment was to keep both the traction force and tillage depth at preset values. The traction and tillage depth were respec-tively set at $4000 \mathrm{~N}$ and $20 \mathrm{~cm}$. Figure 13 shows variations in the traction and tillage depth during the experiment. The steady-state errors of the traction force and ploughing depth were respectively $\pm 4000 \mathrm{~N}$ and $\pm 5.5 \mathrm{~cm}$ over the course of the experiment.
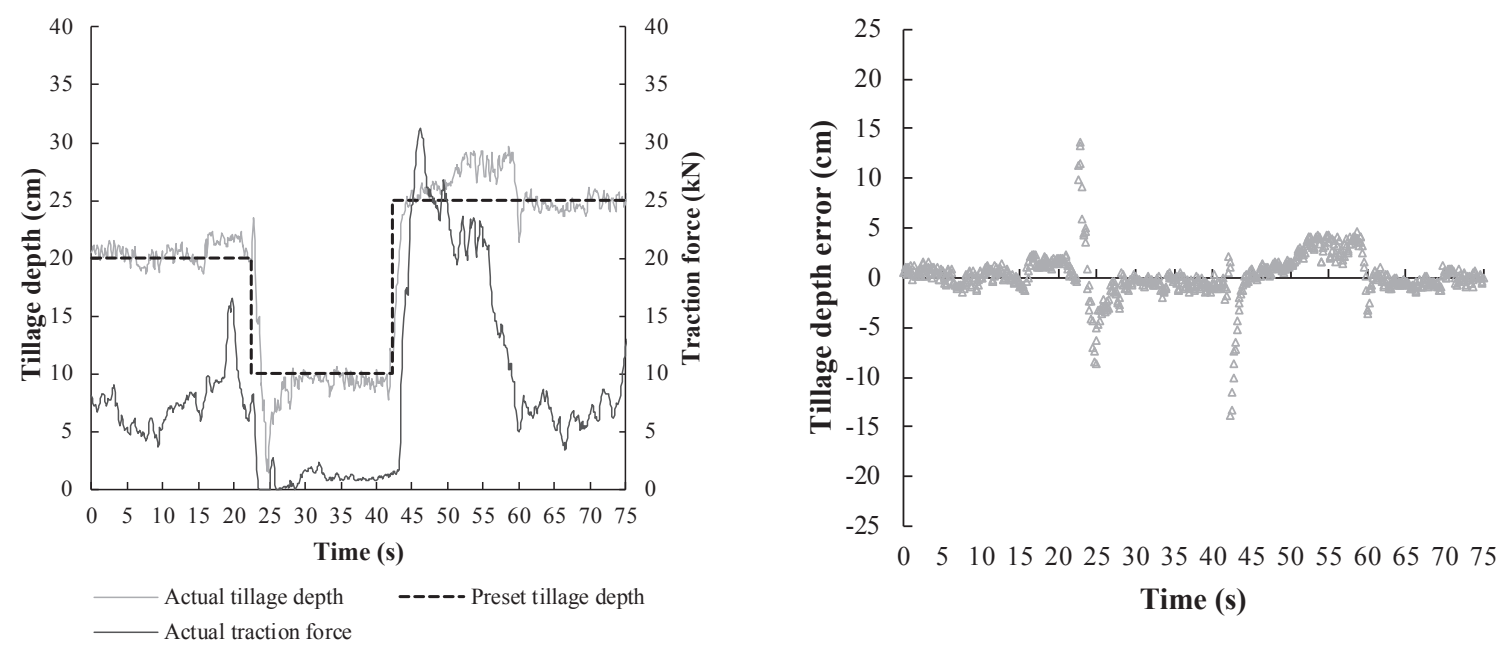

Fig. 11. Actual tillage depth and traction in the depth control experiment. 

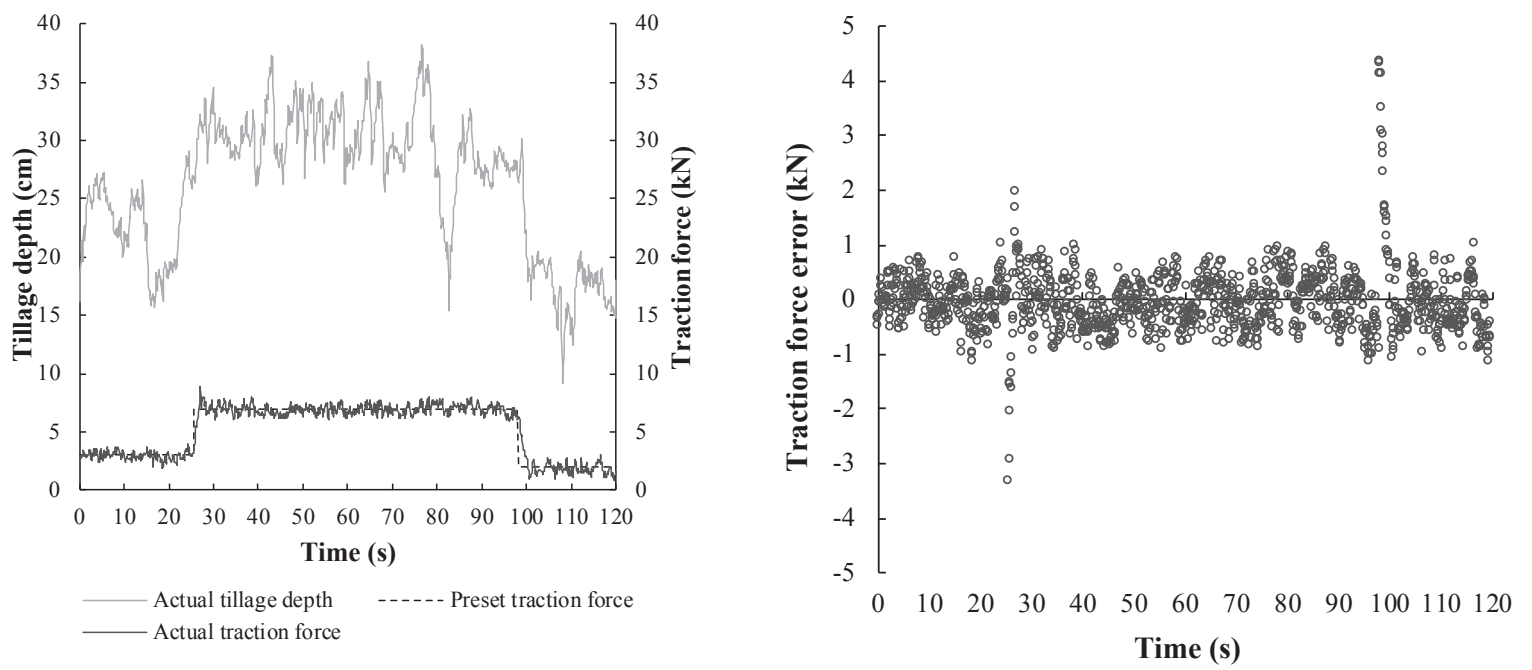

Fig. 12. Actual traction and tillage depth in the traction control experiment.

\section{CONCLUSIONS}

A fuzzy-PID adaptive control algorithm was applied to tractor ploughing. A semiphysical simulation platform of the lifting system of a tractor was built using MATLAB and LabVIEW. Field experiments of ploughing operation with three control conditions were carried out and the test results analyzed.

In the experiment on tillage depth control, when the depth was reduced from 20 to $10 \mathrm{~cm}$ by raising the plough, the adjustment time was $5 \mathrm{~s}$ and the maximum overshoot was 90\%. The response time of the adjustment process was shortened but the stability was reduced by in-creasing the lifting speed of the plough. When the depth was increased from 10 to $25 \mathrm{~cm}$ by lowering the plough, the adjustment time was $18 \mathrm{~s}$ and the maximum overshoot was $20 \%$. Increasing the tillage depth requires the tractor to move forward a certain distance. Owing to the tractor's low speed, the adjustment process had a long response time long but was stable. The steady-state error of tillage depth during the exper- iment was $\pm 2 \mathrm{~cm}$ and the consistency of the tillage depth was good.

In the experiment on traction control, the adjustment of traction was also realized by controlling the tillage depth. When the traction force increased from 3000 to $7000 \mathrm{~N}$, the adjustment time was $1.4 \mathrm{~s}$ and the maximum overshoot was $25 \%$. The adjustment was fast and stable. When the traction force decreased from 7000 to $2000 \mathrm{~N}$, the adjustment time was $2 \mathrm{~s}$ and the maximum overshoot was 51\%. The adjustment was fast but less stable. Owing to the change in soil conditions, the traction force varied greatly at the same tillage depth, and the steady-state error of the traction force during the experiment was larger (i.e., $\pm 1200 \mathrm{~N}$ ).

In the experiment on the joint control of traction and tillage depth, it was difficult to keep both the traction and tillage depth at preset values under the effect of soil conditions, and errors were relatively large (i.e., $\pm 4000 \mathrm{~N}$ and $\pm 5.5 \mathrm{~cm}$, respectively). Future work needs to study the soil conditions and determine reasonable settings of the traction and tillage depth. At the same
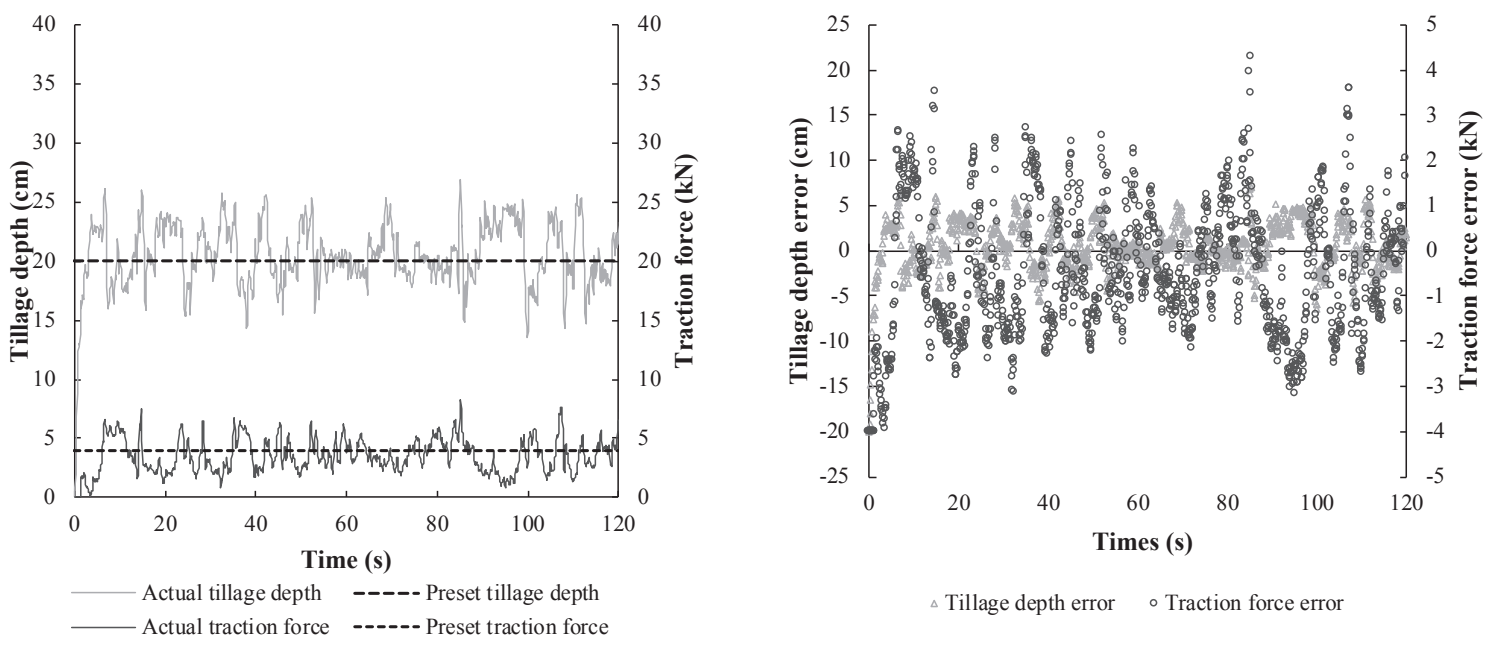

Fig. 13. Actual traction force and tillage depth in the tractor mix control model. 
time, there is a need to study the control of the lifting and falling speeds of the plough such that the adjustment is more rapid and stable.

\section{AUTHOR CONTRIBUTIONS}

Mingsheng LI designed the study, analyzed the data and wrote the paper. Jian LIU designed the target controller and carried out the performance test on the Semiphysical Simulation platform. All authors assisted in editing of the manuscript and approved the final version.

\section{ACKNOWLEDGEMENTS}

The authors acknowledge financial support from the National Key Research and Devel-opment Program of
China (No. 2016YFD0701001) and Chinese Scholarship Council.

\section{REFERENCES}

Johannsen, B.B. 1954 Tractor hitches and hydraulic systems-an implement designer's viewpoint. SAE Technical Papers

Dell Acqua, R., Dell Orto, G. and Guagliumi, R. 1986 Agricultural vehicle electronics-a new hitch control. SAE Technical Papers

X. Ha, T. Cui and D. Zhang. 2017 Development of an electricdriven control system for a precision planter based on a closedloop PID algorithm. Computers and Electronics in Agriculture, 136(15): 184-192

Xie, B., Li, H. and Zhu, Z. 2013 Measuring tillage depth for tractor implement automatic using inclinometer. Transactions of the Chinese Society of Agricultural Engineering, 29(4): 15-21

J. B. W. Roeber, S. K. Pitla and M. F. Kocher. 2016 Tractor hydraulic power data acquisition system. Computers and Electronics in Agriculture, 127(9): 1-14 
